\title{
Às margens do cuidado: regulaçóes de gênero em uma equipe de saúde
}

\section{| ${ }^{1}$ Érika Cecília Soares Oliveira, ${ }^{2}$ Luciane Maria Pezzato, ${ }^{3}$ Rosilda Mendes I}

Resumo: Embasado em uma perspectiva feminista, este artigo analisa como uma equipe de saúde tece as redes de cuidado e define práticas de saúde a partir do percurso de uma usuária. A metodologia utilizada é da pesquisa-intervenção inspirada na perspectiva cartográfica. $\mathrm{Na}$ tentativa de reduzir taxas de mortalidade materno-infantil, a equipe oferece à usuária uma rede que obedece a uma lógica burocrática com regras, normas e regulações. É possível observar como políticas voltadas para a maternidade definem processos de subjetivação responsáveis por formatar as usuárias, desenhando atos performativos enrijecidos. A equipe de saúde acaba por requisitar os corpos das usuárias de diferentes maneiras pelo fato de serem mulheres. Usuárias essas que, na maioria dos casos, são mães e pobres, o que traz singularidades em relação às suas trajetórias e nos modos como são vistas pelas equipes. Laqueadura, pré-natal, cuidados com a casa e (as) os filhas(os), acesso a determinados benefícios, todos juntos constituem elementos que orientam as decisóes das equipes e agem como tecnologias de regulação de gênero capazes de legitimar violências institucionais cotidianas. A politização das práticas técnico-científicas se faz urgente a fim de assegurar que questôes sobre direitos humanos e sociais possam fazer parte do dia a dia das equipes que estão nos territórios.

> Palavras-chave: identidade de gênero; violência; discriminação social; políticas públicas; atenção básica à saúde.

\author{
'Instituto de Psicologia, \\ Universidade Federal de Alagoas. \\ Campus Maceió. Maceió-AL, \\ Brasil (erika.oliveira@ip.ufal.br). \\ ORCID: 0000-0003-4877-0971. \\ ${ }^{2}$ Departamento de Saúde, Clínicas \\ e Instituiçōes, Universidade \\ Federal de São Paulo. Campus \\ Baixada Santista, Santos-SP, Brasil \\ (lucianepezzato@gmail.com). \\ ORCID: 0000-0002-3591-1491 \\ ${ }^{3}$ Departamento de Políticas \\ Públicas e Saúde Coletiva, \\ Universidade Federal de São \\ Paulo. Campus Baixada Santista, \\ Santos-SP, Brasil (rosilda. \\ mendes3@gmail.com). \\ ORCID: 0000-0001-5680-1657
}

Recebido em: 16/05/2017 Aprovado em: 18/03/2018 Revisado em: 05/04/2018 


\section{Introdução}

Esta discussão se insere no contexto de uma investigação mais ampla vinculada a um grupo de pesquisa da Universidade Federal de São Paulo - campus Baixada Santista. Trata-se de pesquisa vinculada ao projeto PPSUS-SP/FAPESP e que teve como parceiros a Secretaria Municipal de Saúde de Santos e o Coletivo Paulista de Investigação em Saúde (COPAIS). Realizada em onze Unidades Básicas de Saúde (UBS) e Unidades de Saúde da Família (USF) de diferentes regióes do município, teve como objetivos analisar as potencialidades da atenção básica como ordenadora das açôes de cuidado em saúde, identificando experiências de cuidado nas quais estão envolvidas(os) usuárias(os) e trabalhadoras(es) dos serviços de atenção básica; analisar as redes formais e informais envolvidas nas situaçóes de cuidado e suas interfaces, bem como identificar estratégias e intervençôes utilizadas para produzir cuidado em rede.

Daquilo que foi visto durante o trabalho de investigação junto às unidades de saúde, chamou-nos a atenção algumas experiências de cuidado que trouxeram questôes sobre o modo como as performances de gênero de usuárias são produzidas no cotidiano dos serviços de saúde, evidenciando as normas regulatórias de gênero que se corporificam nos espaços físicos, nas relaçôes entre profissionais e usuárias(os), na construção de projetos terapêuticos e institucionais, entre outros. Nesse caso, observamos o quanto a incorporação de formas específicas de subjetivar feminilidades e masculinidades se reverte em práticas de produção de saúde (VASCONCELOS; SEFFNER, 2015).

Para amparar nosso olhar nessa discussão, trazemos como referencial analítico as teorizações feministas que afirmam serem as tecnologias de sexo e gênero reinscritas constantemente por meio de operaçôes de repetição e recitação de códigos que ditam o que é ser mulher e homem, investindo-os socialmente como naturais (PRECIADO, 2014; BUTLER, 1987). De acordo com Butler (2002; 2003; 2010), a feminilidade é construída socialmente e resulta numa prática que confere à mulher um lugar tangenciado pelo preconceito dado o caráter natural - e não político - que é conferido à sua existência. A ideia de uma categoria única referente às mulheres revela consequências coercitivas dessa construçâo, sendo visíveis em práticas reguladoras das identidades. Tal constatação é mencionada por inúmeras pesquisadoras, que mostram a infinidade de mulheres que vivem em intricados eixos de classe, raça e cultura e que, por isso mesmo, criam diferenças na qualidade, estilo 
de vida e status social dessas mulheres (HARDING, 1993; HOOKS, 2004; BRAH, 2006; HARAWAY, 1995).

A pluralidade da categoria "mulher" deve ser referida também quando pensamos em questóes como a maternidade. Butler (1987) entende a maternidade como uma realidade institucional mais que instintiva, expressando a interação entre constrangimento e liberdade. O esforço por interpretar os sentimentos maternais como necessidades orgânicas revela o desejo de encobrir a maternidade como uma prática opcional. Entendê-la como uma escolha, por sua vez, implica engendrar vertigem e terror a respeito da possibilidade de se perder as sançóes sociais, de abandonar um posto e um lugar social sólidos por parte daquelas(es) que têm interesse em manter a hegemonia desses lugares destinados às mulheres. Daí a manipulação que resulta na tentativa de fazê-las acreditar o quanto seus corpos são "naturais" (WITTING, 1992). Nesse sentido, Preciado (2008) demonstra como se dá de maneira desigual a institucionalização do corpo feminino e masculino nos circuitos de produção de saber e artefatos biomédicos. Segundo ela, o corpo das mulheres, inclusive daquelas que aparecem como "normais" - as femininas, as heterossexuais, as que não são frígidas nem histéricas, nem putas ou ninfômanas - e que são corpos de "perfeitas mães potenciais”, mesmo esses corpos estão sempre sujeitos à vigilância e regulação.

A fim de perseguir protocolos, muitas vezes o próprio sistema de saúde acaba atuando como regulador sanitário das famílias pobres, em particular de mães e bebês, colocando na figura das agentes comunitárias de saúde (ACS) a responsabilidade de alcançar os objetivos sanitários propostos. Essas acabam por atuar como legítimas "policiais" da maternidade na tentativa de alcançar a redução da mortalidade infantil (ROBLES, 2012). Esse fato, por sua vez, aponta para a necessidade de compreendermos as políticas públicas de saúde como territórios de ensino que atuam como pedagogias engajadas na formatação de corpos marcados por normas regulatórias de gênero (VASCONCELOS; SEFFNER, 2015). Nesse caso, muitas vezes o que impera é uma perspectiva familista que, para restaurar certos pressupostos de harmonia familiar, acabam por ignorar questôes de direitos que envolvem os diferentes sujeitos, como bem aponta Santos (2015) em relação às equipes responsáveis pela assistência social.

A justificativa para a análise que ora faremos ocorre justamente porque essa problemática se repetiu em algumas das unidades de saúde investigadas por nós. Com isso, coloca-se a importância de compreender os sentidos que as políticas de 
saúde em articulação com políticas sociais mais amplas têm sobre as performances das mulheres para as quais são direcionadas, muitas vezes responsabilizando-as e até mesmo culpabilizando-as caso náo sigam o roteiro que foi traçado previamente para elas. Dentre as situações de cuidado acompanhadas, ficou nítido que algumas delas amparavam-se em políticas públicas voltadas para o acompanhamento de recémnascidas(os) e gestantes na tentativa de reduzir o elevado índice de mortalidade materno-infantil do município no qual aconteceu a pesquisa. Colocou-se como questão, desse modo, o fato de que a trajetória de algumas mulheres pela rede de cuidados - sobretudo se grávidas - tem um contorno específico pelo fato de serem mulheres, sendo seus corpos requisitados de diferentes maneiras e para distintos fins. De algum modo, o poder de inscrever condutas por meio do acionamento de pedagogias corporais permite que as práticas de saúde tentem restabelecer a saúde e cuidado através de uma vigilância cotidiana, passível de punição (VASCONCELOS; SEFFNER, 2015). Disso decorrem inúmeras situações em que a violência institucional é legitimada e reproduzida a fim de tentar encaixar as mulheres naquilo que se convencionou considerar "correto" ou "normal", não levando em conta seus desejos e escolhas.

Nesse sentido, ficou evidente o que certas autoras têm chamado de feminização da inclusão social, que pode ser visualizada pelo acesso às mais variadas formas de políticas públicas e que possui, claramente, um viés de gênero, sobretudo quando se tratam daquelas voltadas para o campo da saúde, segurança e defesas sociais (MATOS, 2008; MEYER et al., 2014). Essas políticas, por ditarem regras e regimes de verdade sobre a vida das pessoas, acabam por definir processos de subjetivação que formatam mulheres e homens e embasam as performances de gênero e tecnologias responsáveis por reproduzi-lo cotidianamente. Laqueadura, pré-natal, cuidados com a casa e (as)os filhas(os), acesso a determinados benefícios oriundos de políticas sociais, tudo isso configura-se em açôes e programas que vão, em grande parte, definir e orientar o olhar das equipes de saúde sobre as usuárias. Usuárias essas que, na maioria dos casos, são mães e pobres, o que traz singularidades em relação à suas trajetórias e nos modos como são vistas pelas equipes.

Este artigo busca analisar como uma equipe de saúde tece a rede de cuidados e define práticas de saúde a partir do percurso de uma usuária. Para tanto, apresentamos a história dessa usuária, que chamaremos aqui de Rebeca, que tinha, à época da pesquisa, 18 anos. Durante o ano de 2014, ela morava num barraco na regiáo 
adscrita de uma das USFs por nós pesquisada, território de alta vulnerabilidade, com seu companheiro e um de seus filhos. Rebeca estava grávida e viria a ter outro seu terceiro filho nesse período. $\mathrm{O}$ mesmo nasce com sífilis congênita e, após seu nascimento, seus dois filhos mais novos são retirados pelo Conselho Tutelar quando ela ainda se encontrava na maternidade e sem ter sido avisada previamente. A retirada dos filhos pelo Conselho Tutelar se deu como resultado da anuência coletiva entre diferentes profissionais da rede formal de Rebeca que se reuniam para discutir seu caso. Tivemos oportunidade de participar de algumas reunióes entre conselheiro tutelar, equipe do CRAS e da USF com sua mãe e avó paterna. Além disso, discutiase entre eles a possibilidade de a mesma vir a fazer uma laqueadura, algo que ela, posteriormente, negou-se a realizar. Depois desse acontecimento, Rebeca abandona seu barraco e passa a morar na rua. Posteriormente, somos informadas pela equipe de saúde de que ela ai foi morar com a mãe numa cidade do interior de Sáo Paulo, com quem sempre teve uma relaçấo bastante conflituosa, passando a frequentar uma clínica de reabilitação, já que era usuária de drogas.

\section{Trajetória metodológica}

A pesquisa realizada no período de 2014 a 2016 foi organizada em etapas para o acompanhamento e a produçáo da experiência. Esses passos ocorreram de modo sequencial e/ou concomitante, de acordo com as especificidades do caso/situação de cuidado num processo em que cada momento de pesquisa trouxe consigo o anterior e se prolongou nos seguintes. Inicialmente, realizamos encontros com a equipe de saúde dessa USF para explorar casos e/ou situaçóes marcantes que exigiam a intervençấo em redes, e, em seguida, selecionamos um caso/situação a fim de conhecer as redes formais e informais acionadas e como os diversos atrizes e atores contribuíram ou não para a efetivação das redes de cuidado dessa pessoa. Todo o percurso foi acompanhado da realização de oficinas com os profissionais da rede de serviços para seguir a experiência, (re)definir instrumentos norteadores, discutir e sistematizar os dados produzidos para o seguimento do processo investigativo. Teve como fundamento lançar um olhar sobre a rede de poderes e os jogos de interesses presentes no campo de investigação, desconstruindo verdades e estabelecendo "conversas não inocentes" sobre os acontecimentos, por um lado, e, por outro, compreendendo que a objetividade que buscamos alcançar tem a ver com a 
responsabilidade sobre a prática de pesquisa ora desenvolvida, entendida como um fazer posicionado (HARAWAY, 1995).

Portanto, um importante norteador metodológico para essa investigação partiu da reflexão sobre que tipo de açóes melhor serviriam para dar conta dos inúmeros desafios dos campos pedagógico e profissionais, que incluem as relaçóes entre os sujeitos - que acompanham e que são acompanhados -, o coletivo como força motriz de mudanças subjetivas e o lugar dos métodos e das técnicas.

Tomando como desafio o caráter inventivo da ciência, foram mobilizadas neste estudo diferentes estratégias metodológicas, entre as quais a cartografia, que o configuram como uma pesquisa-intervenção (ROCHA; AGUIAR, 2003; PAULON, 2005).

A roda de conversa foi um dos dispositivos acionados para os encontros, além da construção de cartazes e narrativas escritas e compartilhadas com a equipe de saúde, bem como a realizaçáo de uma entrevista com uma ACS para compreender melhor a história dessa usuária. Também os registros nos diários coletivos de pesquisa, produzidos pelas(os) pesquisadoras(es) após cada encontro, puderam contribuir para a construção de uma escritura afetiva presente nos passos da usuária, evidenciando os impactos que em nós causava. A produção coletiva desses diários de pesquisa (DP) possibilitou uma articulaçáo entre as pesquisadoras em campo, restituindo junto à equipe de saúde os percursos traçados por nós (PEZZATO; L'ABBATE, 2011). A restituição aqui se apoia na perspectiva da Análise Institucional, que "consiste em se centrar numa tarefa - a análise coletiva da situação presente, no presente em função das diversas implicações de cada um com e na situação" (LOURAU, 1993, p. 64). Além disso, transitar pela rede de Rebeca implicou acompanhar seu percurso em outros espaços institucionais, como no Conselho Tutelar e no Centro de Referência de Assistência Social (CRAS).

Após a produção de dados, foi realizada uma leitura minuciosa do material e a definição de três núcleos de sentido que permitiram colocar em evidência as questôes que emergiram da investigação: a) Rebeca: a usuária que "não age como gente"; b) As redes de cuidado (im)postas a Rebeca e c) Políticas públicas e feminização da inclusão social. Todos os procedimentos éticos foram cumpridos e as(os) participantes assinaram o Termo de Consentimento Livre e Esclarecido (TCLE). A pesquisa foi aprovada pelo Comitê de Ética em Pesquisa da Instituição (parecer CEP 674.539, de 28/5/2014). 


\section{Rebeca: a usuária que "não age como gente"}

De acordo com a ACS, Rebeca "caiu" naquela microárea de "paraquedas", ela e o companheiro ocuparam um barraco de um antigo morador que morrera de leptospirose. Sempre que a ACS passava pelo barraco, observava que lá havia uma criança e, um dia, notou também "uma barriguinha ali crescendo", motivo que começou a preocupá-la. É justamente a partir dessa preocupação que uma "luta" começa a ser travada entre a equipe e Rebeca. Um esforço começa a ser assumido na tentativa de que a usuária inicie seu pré-natal, mas essa luta mostra-se insuficiente dado a pouca frequência da mesma nas consultas. Depois de alguns meses, Rebeca começa a frequentar a unidade, mas, segundo a ACS: “[...] sempre com muita dificuldade, pedia as coisas, pedia água, ficava chorando pra ser atendida logo. Ela não gostava de esperar.” Depois de aberto o pré-natal, Rebeca não conseguia comprometer-se a frequentar os atendimentos propostos. Para piorar a situação, a equipe também descobre que o filho dela não possuía carteirinha de vacinação e parecia estar desnutrido. Isso passa a alimentar uma grande preocupação em relação a essa criança. No relato da ACS, nota-se que o companheiro de Rebeca conseguia cooperar um pouco, mas com ela tudo era muito complicado. Observando todas essas dificuldades em dar um tipo de vida mais saudável para a criança é que a ACS pensa que Rebeca "não tá levando, se esforçando", ou ainda: "ela não aderia a nenhum dos caminhos que a gente 'tava' procurando pra ela." Diante disso, comunicam o Conselho Tutelar para tomar alguma providência em relaçáo aos filhos dela.

Ao longo da entrevista, revela-se que Rebeca náo colaborava com nenhuma ação da equipe: consultas referentes ao pré-natal, tratamento da sífilis, laqueadura, higiene da casa e do filho, nada disso parecia ser objeto de investimento da mesma. A partir daí, a equipe começa a "correr contra o relógio" na tentativa de solucionar esse caso, cuidando para amenizar os riscos de vida desse bebê que estava para nascer. A sujeira de Rebeca e sua casa incomodava a todas(os) que dela se aproximavam; é o motorista da unidade que diz: "Pô, tá faltando água lá?.” Segundo a ACS, sua casa parecia um "chiqueiro de porco", um lugar com "rato, tudo sujo, roupa suja, podre”. Em dado momento de sua narrativa, a ACS demonstra uma profunda identificação com Rebeca pelo fato de esta ser mãe como ela. Diz:

[...] pensei até em pedir pra sair do serviço, porque ficou mexendo muito com a minha mente também, até porque eu tenho filhas, né? (ACS). 
E mais adiante:

Tinha vontade, tinha horas de pegar o menino só pra dar um banho. Mas eu pensava: "Ah eu nâo posso fazer isso." Ela [Rebeca] me abraçava no meio da rua, falava que era minha filha mais velha, olha só Deus na minha vida! Daí eu ficava assim meio dividida porque pô, eu sou agente comunitária, eu sou mãe, eu sou cristã [...] (ACS).

Tal identificação assume seu ponto mais crítico nessa passagem, que demonstra a dramaticidade que a existência dessa usuária trouxe para a vida da agente:

[...] fiquei tâo louca que teve um mês que eu comprei um monte de produto de limpeza, pra ficar limpando a minha casa, pra tu ter uma ideia, ficava limpando chão que aquele cheiro tava na minha casa, mas não era (ACS).

Esse desassossego suscitado pela vida de Rebeca leva a agente a designá-la como uma "alma penada", alguém que não parecia gente, pois "não agia como gente". A vida de Rebeca produzindo um efeito chocante sobre o olhar da agente comunitária, que diz ainda:

E o pessoal pensa: "Ah, agente comunitário, mora no bairro", mas antes de eu ser agente comunitária, eu não conhecia, eu nem sabia do mundo que tava ali a minha volta, porque sinceramente (ACS).

Situaçôes-limite, como esta, contribuem para reforçar os próprios limites da atenção primária, do lugar da(o) ACS na comunidade e sua formação profissional.

\section{As redes de cuidado (im)postas a Rebeca}

Figura 1. Rede formal e informal de Rebeca desenhada pela equipe de saúde

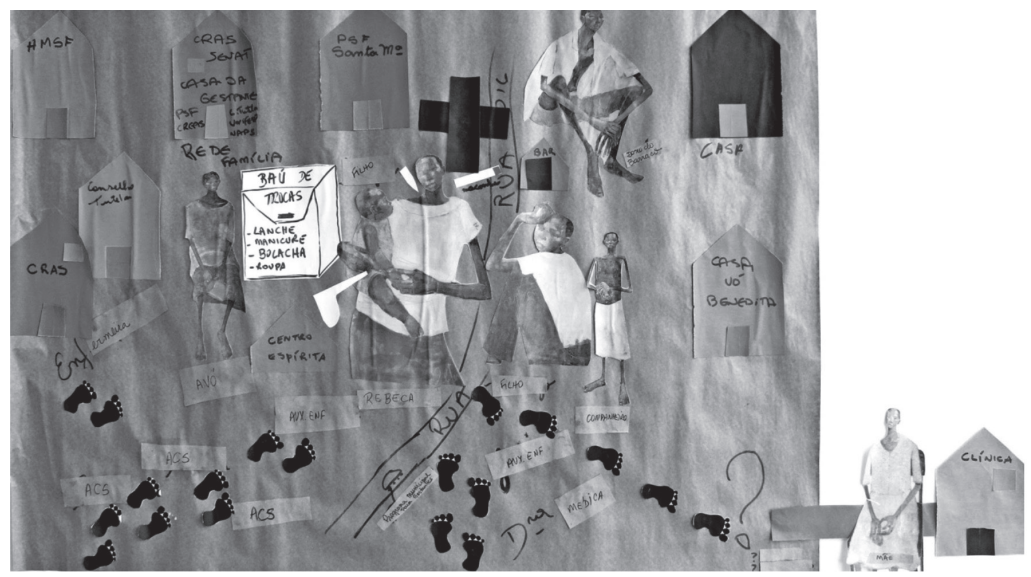

Fonte: Oficina com a Equipe de Saúde. Fotografia tirada pela equipe de pesquisadoras(es). 
A figura 1 foi construída coletivamente com a equipe de saúde com o objetivo de produzir uma síntese sobre a rede formal e informal de Rebeca. O que temos, pois, no produto final é o conjunto de instituições pelas quais a usuária passou: CRAS, Seção Núcleo de Atenção ao Toxicodependente (SENAT), Casa da Gestante, Abrigo, Conselho Tutelar, Maternidade, Núcleo de Apoio Psicossocial (NAPS) e a própria USF, que é marcada por meio de pegadas, mostrando a participação de cada profissional da equipe no tratamento de Rebeca. Além disso, é possível visualizar as redes informais percorridas por ela (centro espírita, bar, a rua, da qual ela tinha sido moradora, o companheiro e os filhos, avó paterna e mãe). Uma dessas redes informais foi desenhada com uma ponte ao lado direito do cartaz: nela é colocada a mãe e a clínica particular para qual Rebeca havia sido enviada pela mãe após ter sido separada de seus filhos, demarcando a distância e, ao mesmo tempo, um desdobramento dessa história. Porém, não foi uma decisão tranquila por parte da equipe inserir sua mãe no cartaz, como consta no registro do Diário:

Quando pegaram uma imagem que disseram representar a mãe da Rebeca, a discussão evoluiu um pouco, pois algumas diziam, "mas nem lembramos o nome dela", outros diziam que ela não estava presente aqui [...], mas depois decidiram que ela entraria, mas fora do papel, distante (DP, 11/3/15).

A ponte que é colocada no cartaz é antecipada por um grande ponto de interrogação, pois até aquele momento não se sabia se esse era, de fato, seu paradeiro (se ela estava numa clínica, se estava com sua mãe, ninguém tinha muita certeza). Apenas um tempo depois, soubemos que Rebeca estava morando com sua mãe, numa cidade do interior. Nesse momento, é possível notar que a equipe sentia que havia feito tudo o que podia e que Rebeca já não era mais sua responsabilidade. Daí compreendermos que, uma vez tendo seguido todas as prescriçôes disponíveis para combater a mortalidade infantil, a equipe coloca essa usuária às margens do cuidado, já não tendo mais recursos para dar continuidade ao seu tratamento.

Figurando no meio do cartaz há uma espécie de "baú de trocas", recurso muito utilizado para conseguir negociar com a usuária o seu próprio tratamento, a fim de que seguisse o protocolo do cuidado à gestante de alto risco. Para tanto, era necessário dar-lhe algo em troca, seja um lanche, xampu, roupas, coisas do tipo. Como ficou registrado no Diário: "A enfermeira nos contou que sempre que vai algum profissional da equipe até a casa dela para convidá-la para uma consulta ela pede algo em troca: sucos, biscoitos...", ou em outra passagem: "A médica já chegou 
a pintar as unhas de Rebeca” (DP, 26/11/14). Será que esta cultura da troca acontece só no caso da Rebeca?

Para os antropólogos, esta relação vem de longa data. De acordo com Lanna (2000, p. 175), Marcel Mauss já apontava em seus estudos que a constituição da vida social estava vinculada a "um constante dar-e-receber". Definida de modo amplo, essas "práticas de trocas", ou "teoria das dádivas", podem adquirir variadas formas de retribuição em seus diferentes tempos e lugares. Como também podem produzir uma relação de aliança, aproximação. Em seu texto, Mauss (2003, p. 188) questiona: "Que força existe na coisa dada que faz que o donatário a retribua?” Seria uma obrigação? Lacerda e Martins (2013, p. 195) definem esta teoria como um sistema de ação social complexo, constituído a partir da tríade de doação, recepção e retribuição.

Voltando à figura 1: ao redor de Rebeca, que carrega seu filho recém-nascido nos braços, encontram-se pacotes de cocaína, crack, o que mostrava que ela consumia outras drogas além da maconha, que, por vezes, a ACS pôde vê-la consumindo. Só não tinham certeza de qual dessas ela usava.

De acordo com as discussões realizadas ao longo dos encontros de pesquisadoras(es) sobre essa situação de cuidado, parecia-nos que, para a equipe, Rebeca não conseguia dispor da rede, é como se a rede não "servisse" para ela, dela não desfrutava nem conseguia acioná-la em proveito próprio: ela não tinha documento, Bolsa Família ou qualquer benefício. Ocupava, portanto, um não lugar, porque talvez não soubesse ocupar outro, porque não tinha dado tempo. Tanto é que quase termina sua trajetória novamente lançada na rua, agora também sem seus filhos. A rede "falha", Rebeca "falha". Usufrui tão pouco da rede que suas tentativas de cuidar de si se dão por meio de barganhas face a face com a equipe: tenta fazer transaçôes, é mal compreendida por isso.

Nessas discussóes, perguntas sobre o manejo das redes de cuidado se colocavam: afinal, quem, de fato, as articulava, usuárias(os) ou serviços? Para nós, parecia que Rebeca não manejava sua rede, pois não tinha conhecimento suficiente sobre ela a ponto de caminhar nela. De certa forma, ela recusava-se a caminhar por essa rede se isso implicasse que teria que dar algo em troca do jeito que a rede esperava que ela desse. Acreditamos que a rede de Rebeca, assim como da maioria das(os) usuárias(os) dos serviços, era (im)posta a ela, diante dessa rede náo lhe era permitido negociar outras possibilidades de ser. A rede que a equipe tentou ofertar para Rebeca foi aquela que a própria equipe dispunha, que obedecia a uma lógica burocrática 
organizacional (MERHY et al., 2014), com suas regras, normas, regulações. A equipe, por sua vez, ao expor a rede, mostrava o quanto a mesma tinha furos, poucos recursos e tecnologias para dar conta da complexidade de histórias como as de Rebeca, histórias que não são previsíveis, histórias que são reais.

Algumas(ns) autoras(es) já chamaram a nossa atenção para o fato de que as pessoas, quando portadoras de uma determinada "doença", acabam sendo compreendidas apenas a partir desse rótulo, todo o resto sendo apagado (MERHY et al., 2014; ROZEMBERG; MINAYO, 2001). Para algumas(ns) profissionais da equipe, não havia dúvida quanto à imposição dos protocolos, principalmente quando dizia respeito ao fato de Rebeca estar gestante e com sífilis. Não se discutia e nem se poupavam esforços para segui-la onde estivesse para aplicar-lhe a injeção para o tratamento da sífilis. A simples ideia de apagar a vontade - vontade difícil, relutante - de Rebeca através da coerção, a fim de perseguir o protocolo a qualquer custo, parecia-nos sempre o ápice do olhar biologizante, reducionista. Ou, ainda, parecia traduzir um cotidiano sobrecarregado, em que parecia entrar na esfera do impossível um olhar para a usuária que pudesse sair do biológico e apostar num "fazer junto" com ela; algo que demandaria tempo, investimento que nem sempre a equipe dispunha, ou mesmo o sistema permitia. É claro, para que as coisas funcionassem, seria muito mais fácil que Rebeca fosse colaborativa: casa limpa, filhos alimentados, vacinas em dia, frequência no pré-natal, enfim, ela teria que deixar de ser quem ela era, para ser aquilo que a equipe precisava que ela fosse. A pergunta que se instaurava, pois, era: como cuidar de uma usuária que não possuía os atributos que se espera dela? É possível produzir cuidado nessas condiçôes? Para algumas(ns) autoras(es), o cuidado é produzido na relação, no encontro entre trabalhadoras(es) e usuárias(os), numa produção mútua, com compartilhamento de saberes, valores, modos de levar a vida (MARTINES; MACHADO, 2010).

É justamente aí que reside o que Merhy et al. (2014) chamam de "ponto nevrálgico" dos processos de produção de cuidado em saúde: a anulação das possibilidades de vidas que habitam os sujeitos e sua substituição por estigmas ou produçôes de identidades universais que passam a representar as apostas terapêuticas. Desse modo, é a Mulher (essa com M maiúsculo, universal, táo problematizada pelas feministas) que a equipe esperava encontrar: boa mãe, boa dona de casa, boa esposa, e que, ao não vê-la, partia para uma ofensiva para encontrá-la/fazê-la existir a qualquer custo. E precisamente por não se ajustar naquilo que deveria ser, por recusar aquela rede 
institucionalizada, aquela rede furada, que a usuária é expelida, banida, lançada para longe, no meio dos buracos da rede, correndo o risco de ser abandonada, substituída e impedida de produzir suas próprias redes, pois a equipe, no seu cotidiano, possui muitas Rebecas.

Merhy et al. (2014) adverte sobre a frequência com que as equipes de saúde, centradas nas suas próprias lógicas de saberes, muitas vezes veem na(o) usuária(o) alguém desprovida(o) de conhecimento. Desse encontro resulta uma assimetria que não inclui a diferença e, mais ainda, transforma-a em desigualdade de saber. Ao mesmo tempo, pudemos observar que as equipes vivem capturadas pelos protocolos impostos institucionalmente e pouco conseguem refletir sobre situaçóes-limite, complexas, como a de Rebeca. Perguntas sobre o que a fez levar uma vida como aquela não eram formuladas. No entanto, para a equipe e até mesmo para seus familiares, aquilo só acontecia porque ela não era ajuizada, porque não tinha força de vontade, porque não gostava de trabalhar. A experiência complexa não era colocada como possibilidade: ter sido rejeitada pela mãe na infância, ter um "caso" com o padrasto, ter engravidado com apenas 15 anos. ${ }^{1}$ Sob esse ponto de vista, Rebeca não passava de uma perdedora, ela não produzia agenciamento de nenhuma ordem. Depois, pudemos observar que a recusa de Rebeca em fazer a laqueadura, dando como desculpa a religiâo, poderia ser identificada como uma forma de se apropriar do próprio corpo e, assim, produzir resistências. Ao acompanhar essa história, pudemos observar como o corpo de Rebeca era uma geografia de disputas, onde ela o perdia para retomá-lo, em alguma medida, em seguida: corpo-comércio no caso da prostituição, corpo possível de ficar prenhe novamente. Corpo que, no último momento, é "salvo" pela mãe, que não fica desamparado por completo. Disputas essas, vale ressaltar, de poder; incrível ver o quanto Rebeca, de alguma forma, não abria mão do poder que possuía, por menor que ele fosse. Rede desmontada, remontada.

Restam-nos algumas questôes: a equipe tinha recursos disponíveis para trazê-la para dentro da rede existente? A rede oferecia oportunidades e recursos adequados para acolher Rebeca como ela era?

Parecia-nos que, para a equipe, Rebeca "não queria caminhar pela rede". Acreditamos que esse ponto de vista - da vontade, do querer - é que tenha determinado muitas açóes em torno dela. Talvez tivesse sido diferente se fosse levado em consideração que se a usuária não dispunha da rede é porque, provavelmente, 
não tinha "condiçôes" de fazê-lo (emocionais, sociais, econômicas, culturais). Afinal, quem deseja sofrer com a sífilis? Ter partos complicados? O olhar previsível de que fala Merhy et. al. (2014), ao ser lançado para Rebeca, já sabe tudo o que será encontrado: em nenhum momento ele duvida de que ela realmente não pode rearranjar a própria existência. Espera-se que, em um contato de poucos meses com ela, tudo se modifique, a começar por ela mesma. Isso pode ser resumido nessa frase: "Ao passar pela porta de um serviço de saúde, parece que esse outro é convidado a deixar toda vida que traz da rua do lado de fora" (MERHY et. al., 2014, p. 155). Cabe chamar a atenção aqui para o fato de que a figura escolhida por nós para representar Rebeca no cartaz elaborado pela equipe foi a de uma mulher negra. Isso porque, segundo Werneck (2016), é justamente a população negra aquela que mais acessa o Sistema Único de Saúde e, consequentemente, a que sofre as mais variadas violências decorrentes do racismo institucional ali presente. Dentre essas violências, a própria invisibilidade de discussões específicas sobre a saúde da população negra é bem paradigmática. Mas a usuária em questão era uma mulher branca, algo que foi informado pela equipe no dia de produção desse cartaz. Mesmo assim, gostaríamos de sublinhar a necessidade de que a perspectiva interseccional figure em discussões desse tipo. Em outro trabalho, discutimos essa perspectiva, lembrando Crenshaw (2002), para quem as diferenças existentes entre as mulheres fazem toda a diferença, pois pensá-las desarticuladamente implica obscurecer opressóes responsáveis por situaçôes de discriminação e violências. No caso da discussão aqui apresentada, é preciso levar em consideraçáo o modo como certas políticas e açôes voltadas para mulheres pobres podem ser responsáveis por inscrever papéis naturalizadores e essencialistas, muitos deles voltados para sua função reprodutiva.

Isso mostra a complexidade que eixos de subordinaçáo, como classe social e gênero, nos colocam, apontando para o fato de que precisam ser discutidos em interação, como bem argumenta Fraser (2006). Desse modo, é preciso pensar que tais discriminaçôes, exclusões e violências se articulam em torno de gênero, raça, classe social, entre outros marcadores sociais das diferenças, aspecto que os feminismos da terceira onda tão bem problematizaram a partir das vozes de autoras negras, lésbicas, terceiro-mundistas, periféricas, que mostravam a heterogeneidade de subalternizaçóes vivenciadas pelas diferentes mulheres. 


\section{Políticas públicas e feminização da inclusão social}

De acordo com Matos e Paradis (2014), os anos 1990 foram anos de neoliberalismo e de reorganizaçáo do patriarcado dentro do Estado a partir do capitalismo financeiro internacional. O Estado patriarcal, no curso de regimes democráticos, chegou, nesse período, à sua posição mais opressora em termos de discriminação de gênero, passando a recrutar o trabalho feminino do cuidado nas políticas sociais e incluindo gênero (como uma variável despolitizada) como tema transversal das políticas públicas. Na América Latina, esse período é caracterizado por planos sociais compensatórios destinados a reparar as difíceis condiçóes materiais de existência de amplos setores da população, que adquirem na modalidade de políticas focalizadas um modo de enfrentar a situação (ANZORENA, 2010).

Tais políticas afetam diretamente as mulheres, pois as localiza como destinatárias privilegiadas dessas medidas paliativas. Os programas de transferência de renda, por exemplo, partem da responsabilização das famílias, sobretudo das mulheres, para administrar o cotidiano com os valores monetários recebidos (SILVA E SILVA, 2007; 2014; YASBEK, 2012). Com o objetivo de superar a pobreza intergeracional, tais programas preveem certos impactos na vida das pessoas, como a redução da pobreza, a formação de capital humano com foco na saúde, educação e nutrição, tendo como efeitos o aumento na matrícula escolar e da cobertura em relação ao controle de crescimento de crianças e controle médico preventivo. A mulher é a articuladora por excelência dessas políticas, dela espera-se que consiga seguir os protocolos direcionados para que as mesmas surtam algum tipo de resultado. Meyer et al. (2014) veem nesse processo uma responsabilização das mulheres - sobretudo as mães e pobres -, já que as mesmas são posicionadas como "alvo" de políticas e programas de inclusão social. Acredita-se, nesse caso, em uma suposta "natureza feminina" capaz de prestar cuidados às(aos) familiares, a ponto de superar situaçóes de vulnerabilidades ou, ao menos, enfrentá-las. Pesquisas sobre o Bolsa Família, por exemplo, mostram como se dão as regulações sobre o cotidiano dessas mulheres, que muitas vezes são controladas, em relação ao modo como utilizam o dinheiro que recebem, pelas(os) profissionais, que adentram em suas casas para conferir como se deu tal uso (AHLERT, 2013; PIRES, 2013).

No âmbito da saúde, o Programa Rede Cegonha, com vistas a dar assistência à gestação, parto e maternidade, perfila-se ao lado da maioria das políticas de saúde 
voltadas para o atendimento das mulheres no Brasil (VASCONCELOS; SEFFNER, 2015). Se, por um lado, e seguindo a mesma linha das políticas de transferência de renda, ele implica grande reconhecimento de cidadania e efetivação do direito de acesso à saúde; por outro, coloca dilemas como a reiteração de normalizaçôes de mulheres, voltando-as para a maternidade e invisibilizando discussões como liberdade de escolha da maternidade, bem como a legalização ou descriminalização do aborto, levando, mais uma vez, à crença de que a anatomia é o destino. Diferentes pesquisas mostram como a maternidade é produzida e incentivada em programas e açôes de diferentes setores, com o pai ocupando sempre um lugar coadjuvante (MEIRA; TRAVERSO-YEPEZ, 2010; SELL, 2012; CADONÁ; STREY, 2014).

Diante disso, é impossível pensar as redes de cuidado de qualquer usuária(o) sem levar em conta os eixos de diferenciaçáo e poder que a(o) constitui, o que leva à ideia de que desigualdade social deve ser articulada e interseccionada com gênero, raça-etnia, orientação sexual, estilo de vida, nacionalidade, região etc. Isso permite observar que a história do quase-percurso de Rebeca pela rede é uma história de cuidado, mas é a trajetória de uma mulher por uma rede de cuidados e não um homem. E como mulher, seu corpo é requisitado de diferentes maneiras. Não bastasse isso, outro ponto a ser problematizado reside no fato de que essas políticas que responsabilizam as mulheres também são responsáveis por incluir um maior número de mulheres nas profissões que se voltam para executá-las. Nesse sentido, é preciso discutir sobre a precarização do trabalho dessas profissionais e o quanto esse fator auxilia no sentido de que as redes produzidas sejam mais frágeis e, uma vez acionadas num cotidiano de trabalho intenso, cooperam para que certos estereótipos sejam reforçados, colocando muitas vezes equipes e usuárias(os) num campo de grandes tensôes. Em meio a tudo isso, discussôes sobre políticas públicas e sociais podem levar a refletir sobre o agir profissional. De acordo com Schraiber (2012), as práticas profissionais delimitam a produção social de um trabalho e, muitas vezes, as dificuldades para executá-las estão associadas com obstáculos culturais e políticoideológicos. É necessário, pois, uma politização das práticas técnico-científicas, de modo que se consiga assegurar que questóes sobre direitos humanos e sociais possam fazer parte do dia a dia das equipes que estão nos territórios. 


\section{Considerações finais}

Em nenhum momento tivemos a oportunidade de conhecer Rebeca pessoalmente, embora falemos dela incansavelmente nos encontros e na tessitura dos diários. Em dado momento, escrevemos uma espécie de "retrato de Rebeca", a fim de restituir para a equipe o olhar que íamos construindo sobre ela, com base na diversidade de vozes que tentavam descrevê-la. Também tínhamos como objetivo lançar luz sobre o lugar ocupado por ela naquele território e sua relação com os equipamentos disponíveis no "cardápio" oferecido às(aos) usuárias(os) do SUS do município pesquisado. Percebemos, ao ler esse retrato para a equipe, que sobre essa usuária iam sendo esboçados vários retratos, todos eles responsáveis por trazer concepçôes a respeito de cuidado, saúde, direito e desigualdades sociais, gênero, entre outros. Esses retratos atravessavam as práticas e discursos de todas(os) as(os) envolvidas(os) na pesquisa, formando, em muitas ocasiôes, um campo de tensionamento entre equipe e pesquisadoras.

Para nós, ficou evidente que esse cuidado se deu exclusivamente sobre um corpo a ser normatizado, a fim de que se pudesse garantir o nascimento do seu filho. Diante disso, sobressaiu a concepção de que existe um tipo de mulher merecedora de cuidados em detrimento daquelas que, por seu caráter "desviante", são colocadas às margens, não sendo merecedoras de conhecer e desfrutar de seus direitos. Isso, em última instância, aponta para um limite da própria atenção básica. Pudemos perceber uma equipe articulada que tentou construir (ou negociar) possibilidades para atender suas necessidades com os recursos e conhecimentos que dispunham. Uma equipe sem recursos, sem tecnologias para dar conta da complexidade das histórias que chegam até ela.

Como pesquisadoras do campo feminista e da saúde coletiva, preocupadas com a transformação social, concluímos este artigo considerando que uma pesquisa orientada para a intervenção social tem como tarefa primordial a desnaturalização das desigualdades. Esse exercício se faz por meio da historicizaçáo da realidade, de um olhar atento para as relações de poder, focalizando, principalmente, em seus efeitos: silenciamento, estigmatização, deslegitimação, inferiorização e prescrições responsáveis por legitimar exclusōes e perpetuar violências que, de outro modo, ficariam invisibilizadas. ${ }^{2}$ 


\section{Agradecimentos}

Nossos agradecimentos ao grupo de pesquisadoras(es) do NN, pois as reflexóes sobre cuidado em saúde e redes aqui realizadas não teriam sido possíveis sem os debates realizados nos encontros do grupo.

\section{Referências}

AHLERT, M. A. A “precisão" e o "luxo": usos do benefício do Programa Bolsa Família entre as quebradeiras de coco do Codó (MA). Rev Polit Trab, n. 38, p. 69-86, abr. 2013.

ANZORENA, C. "Mujeres": destinatárias privilegiadas de los planes sociales de inicios del siglo XXI: reflexiones desde una perspectiva crítica de género. Rev Estud Fem, v. 18, n. 3, p. 725-46, set.-dez. 2010.

BRAH, A. Diferença, diversidade, diferenciação. Cad Pagu, n. 26, p. 329-76, jan.-jun. 2006

BUTLER, J. Variaciones sobre sexo y género: Beauvoir, Witting y Foucault. In: BEHABIB, S.; CORNELL, D. (Orgs.). Feminismo como crítica da modernidade. São Paulo: Rosa dos Tempos, 1987, p. 303-326.

BUTLER, J. Criticamente subversiva. In: JIMÉNEZ, R. M. Sexualidades transgressoras: uma antologia de estudios queer. Barcelona: Icaria, 2002, p. 55-81.

. Problemas de gênero: feminismo e subversão da identidade. Rio de Janeiro: Civilização Brasileira, 2003.

. Corpos que pesam: sobre os limites discursivos do sexo. In: LOURO, G. L. O corpo educado: pedagogias da sexualidade. 3. ed. Belo Horizonte: Autêntica Editora, 2010, p. 151-72. CADONÁ, E.; STREY, M. N. A produção da maternidade nos discursos de incentivo à amamentação. Rev Estud Fem, v. 22, n. 2, p. 477-499, maio-ago. 2014.

CRENSHAW, K. Documento para o encontro de especialistas em aspectos da discriminaçáo racial relativos ao gênero. Estudos feministas, v. 10, n. 1, p. 171-188, jan. 2002.

FRASER, N. Da redistribuição ao reconhecimento? Dilemas da justiça numa era "póssocialista”. Cadernos de Campo. São Paulo, v. 14-15, p. 231-239, 2006. Disponível em: <http:// dx.doi.org/10.11606/issn.2316-9133.v15i14-15p231-239>. Acesso em: 22 mar. 2016.

HARAWAY, D. Saberes localizados: a questão da ciência para o feminismo e o privilégio da perspectiva parcial. Cad Pagu, n. 5, p. 7-41, 1995.

HARDING, S. A instabilidade das categorias analíticas na teoria feminista. Rev Estud Fem, n. 1, p. 7-31, 1993. 
HOOKS BELL. Mujeres negras. Dar forma a la teoría feminista. In: HOOKS BELL et al. Otras inapropiables: feminismos desde las fronteras. Madrid: Editorial Traficantes de Sueños, 2004, p. 33-50.

LACERDA, A.; MARTINS, P. H. A dádiva no trabalho dos Agentes Comunitários de Saúde: a experiência do reconhecimento do amor, do direito e da solidariedade. Realis, Revista de Estudos antiutilitaristas e Pós-coloniais, v. 3, n. 1, p. 194-203, jan.-jun. 2013.

LANNA, M. Nota sobre Marcel Mauss e o ensaio sobre a dádiva. Rev Sociol Polit, n. 14, p. 173-194, jun. 2000.

LOURAU, R. René Lourau na UERJ - 1993: análise institucional e práticas de pesquisa. Rio de Janeiro: Editora da UERJ, 1993.

MARTINES, W. R. V.; MACHADO, A. L. Produção de cuidado e subjetividade. Rev Bras Enferm, v. 63, n. 2, p. 328-33, mar.-abr. 2010.

MATOS, M. Teorias de gênero ou teorias e gênero? Se e como os estudos de gênero e feministas se transformaram em um campo novo para as ciências. Rev Estud Fem, v. 16, n. 2, p. 333-57, maio-ago. 2008.

MATOS, M.; PARADIS, C. G. Desafios à despatriarcalização do Estado brasileiro. Cader Pagu, n. 43, p. 57-118, jul.-dez. 2014.

MAUSS, M. Ensaio sobre a dádiva. Forma e razão da troca nas sociedades arcaicas. In: MAUSS, M. Sociologia e Antropologia. V. II. São Paulo: Edusp, 2003, p. 183-294.

MEIRA, V. R; TRAVERSO-YEPEZ, M. A. A maternidade na política de humanização dos cuidados ao bebê prematuro e/ou de baixo peso: Programa Canguru. Rev Estud Fem, v. 18, n. 1, p. 61-80, jan.-abr. 2010.

MERHY, E. E. et al. Redes Vivas: multiplicidades girando as existências, sinais da rua. Implicaçóes para a produção do cuidado e a produção do conhecimento em saúde. Saúde Debate, n. 52, p. 153-64, out. 2014.

MEYER, D. E. et al. Vulnerabilidade, gênero e políticas sociais: a feminização da inclusão social. Rev Estud Fem, v. 22, n. 3, p. 885-904, set.-dez. 2014.

PAULON, S. M. A análise de implicação como ferramenta na pesquisa-intervenção. Psicol e Soc, v. 17 , n. 3, p. 18-25, set.-dez. 2005.

PEZZATO, L. M.; L'ABBATE, S. O uso de diários como ferramenta de intervenção da Análise Institucional: potencializando reflexóes no cotidiano da Saúde Bucal Coletiva. Physis, v. 21, n. 4, p 1.297-1.314, out.-dez. 2011.

PIRES, F.F. Comida de criança e o Programa Bolsa Família: moralidade materna e o consumo alimentar no semi-árido. Rev Polit Trab, n. 38, p. 123-135, abr. 2013. 
PRECIADO, B. Testo yonqui. Madrid: Editorial Espasa Calpe, 2008.

PRECIADO, B. Manifesto contrassexual: práticas subversivas de identidade sexual. São Paulo: n-1. Edições, 2014.

ROBLES, A. F. Las agentes comunitarias de salud en el Brasil contemporaneo: la "policia amiga" de las madres pobres. Sexualidad, Saludy Sociedad, n. 12, p. 92-126, 2012.

ROCHA, M. L.; AGUIAR, K. F. Pesquisa-intervenção e a produção de novas análises. Psicol Ciênc e Prof, v. 23, n. 4, p. 64-73, dez. 2003.

ROZEMBERG, B.; MINAYO, M. C. S. A experiência complexa e os olhares reducionistas. Cienc Saude Colet, v. 6, n. 1, p. 115-23, jan. 2001.

SANTOS, C. M. Curto-circuito, falta de linha ou na linha? Redes de enfrentamento à violência contra mulheres em São Paulo. Estud Fem, v. 23, n. 2, p. 557-600, maio-ago. 2015.

SCHRAIBER, L. B. Necessidades de Saúde, Políticas Públicas e Gênero: a perspectiva das práticas profissionais. Cienc Saude Colet, v. 17, n. 10, p. 2.635-44, out. 2012.

SELL, M. "Minha mãe ficou amarga": expectativas performances de maternidade negociadas na fala-em-interação. Rev Estud Fem, v. 20, n. 1, p. 153-172, jan.-abr. 2012.

SILVA E SILVA, M. O. O Bolsa Família: problematizando questôes centrais na política de transferência de renda no Brasil. Cienc Saude Colet, v. 12, n. 6, p. 1.429-39, nov.-dez. 2007.

. Panorama geral dos programas de transferência de renda na América Latina e Caribe. Rev Pol Publ, número especial, p. 299-306, jul. 2014.

VASCONCELOS, M. F. F.; SEFFNER, F. A pedagogia das políticas públicas de saúde: norma e fricçôes de gênero na feitura de corpos. Cad. Pagu, v. 44, p. 261-97, jun. 2015.

WERNECK, J. Racismo institucional e saúde da população negra. Saúde Soc., v. 25, n. 3, p. 535-549, jul.-set. 2016.

WITTIG, M. No se nace mujer. In: WITTIG, M. El pensamiento heterosexual y otros ensayos. Madrid: Editorial Egales, 1992, p. 31-43.

YASBEK, M. C. Pobreza no Brasil contemporâneo e formas de seu enfrentamento. Serv Soc Soc, n. 110, p. 288-322, abr.-jun. 2012.

\section{Notas}

${ }^{1}$ Essas informações foram dadas pela avó paterna e pela mãe de Rebeca durante uma reunião acionada pelo Conselho Tutelar da qual fizemos parte.

${ }^{2}$ E. C. S. Oliveira participou da concepção do artigo, sistematização, análise dos resultados e revisão final do artigo. L. M. Pezzato colaborou na concepção do artigo, sistematização, análise dos resultados e revisão final do artigo. R. Mendes realizou a análise dos resultados e a revisão final do artigo. 


\section{Abstract}

On the margins of care: gender regulations in a health care team

From a feminist perspective, this article analyzes how a healthcare team weaves care networks and defines health practices from the course of a female user. The methodology used is the intervention research inspired by the cartographic perspective. In the attempt to reduce mother-and-child mortality rates, the staff offers female user a network that obeys a bureaucratic logic with rules, norms and regulations. We can notice how policies for maternity define processes of subjectivation responsible for shaping the female users, outlining rigid performative acts. The healthcare team eventually requires the female users' bodies in different ways by the fact that they are women. In most cases those users are mothers and poor, which involves singularities in relation to their trajectories and to the way the teams regard them. Tubal ligation, pre-natal care, care with house and children, access to certain benefits, together are elements that guide the staffs' decisions and act as technologies for gender regulation able to legitimate quotidian institutional violence. The politicization of the technical-scientific practices becomes urgent in order to ensure that issues on human and social rights may be part of the daily routine of teams that work in those territories.

> Keywords: gender identity; violence; social discrimination; public policies; primary health care. 